\title{
Research on Collecting Copper from Chalcopyrite by Flotation in Yunnan
}

\author{
Bowen Yang, Guzhang Zhuang * and Chunmei Wang
}

Faculty of Land Resource Engineering, Kunming University of Science and Technology, Kunming 650093, china and State Key Laboratory of Complex Nonferrous Metals Resource Clean Utilization, Kunming 650093, China

Keywords: copper; chalcopyrite; flotation.

\begin{abstract}
Based on the properties analysis of the chalcopyrite and the phase analysis of the chalcopyrite, collecting copper from the chalcopyrite by flotation was determined. The effects of grinding fineness, the dosage of dispersant and the dosage of collector were researched. The grinding fineness as $90 \%$, water glass as dispersant $400 \mathrm{~g} / \mathrm{t}$ and xanthate as collector $170 \mathrm{~g} / \mathrm{t}$, twostage scavenging and three-stage cleaning, at this conditions, $22.65 \%$ copper was obtained with a recovery of $89.85 \%$. The good mineral processing index was got.
\end{abstract}

\section{Introduction}

As the important elements of modern industrial production, copper is widely used in materials, pharmaceuticals, chemical, steel, energy and other fields (D. Xixiang, 2006, Z. Chunshu, 1988, Z. Chunshui, 1998, D. Xixiang, 1986). Copper has an important economic value. In china the main raw material of copper is chalcopyrite. In recent years copper is already in short a supply metal with technological and economic development. Due to the continuous exploitation of mineral resources, the ore is more difficult to process with ore increasingly poor, fine and miscellaneous.

There is a place with rich chalcopyrite resource in Yunnan province. Based on the properties analysis of the chalcopyrite and the phase analysis of the chalcopyrite, we study on mineral processing technology of this chalcopyrite and obtain a qualified concentrate of copper. It will be benefit on making use of this chalcopyrite recourse.

\section{Ore Property}

Table 1.1 Multi-element analysis of ore \%

\begin{tabular}{lllllllllll}
\hline element & $\mathrm{S}$ & $\mathrm{Cu}$ & $\mathrm{Pb}$ & $\mathrm{Zn}$ & $\mathrm{CaO}$ & $\mathrm{MgO}$ & $\mathrm{Al}_{2} \mathrm{O}_{3}$ & $\mathrm{SiO}_{2}$ & $\mathrm{Fe}$ & $\mathrm{C}$ \\
content & 5.87 & 0.70 & 0.05 & 0.028 & 0.98 & 0.98 & 6.12 & 39.98 & 0.8 & 0.56
\end{tabular}

From table1.1, this ore contains principally of copper, quartz and aluminum oxide, copper is the valuable component and silica and aluminum are the gangue. This ore is simple chalcopyrite and is provided with few impurities of non-ferrous metal.

Table 1.2 Phase analysis of copper

$\begin{array}{lcccc}\text { copper mineral } & \text { Conjunction } \mathrm{Cu} & \text { Free } \mathrm{Cu} & \text { chalcopyrite } & \text { Total } \mathrm{Cu} \\ \text { Content/\% } & 0.02 & 0.04 & 0.64 & 0.7 \\ \text { Percentage/\% } & 2.87 & 5.71 & 91.42 & 100\end{array}$


From table1.2, the main form of copper is chalcopyrite; the contents of conjunction $\mathrm{Cu}$ and free $\mathrm{Cu}$ are very low. The percentage of chalcopyrite is $91.42 \%$. We can think that chalcopyrite is the total copper.

Table 1.3 X-ray diffraction analysis

\begin{tabular}{ccc}
\hline mineral & formula & Content \\
\hline chalcopyrite & $\mathrm{CuFeS}_{2}$ & 8.43 \\
quartz & $\mathrm{SiO}_{2}$ & 32.86 \\
kaolin & $\mathrm{Al}_{2} \mathrm{Si}_{2} \mathrm{O}_{5}$ & 15.23 \\
ankerite & $\mathrm{CaMg}\left(\mathrm{CO}_{3}\right)_{2}$ & 4.56 \\
other & & 20.23 \\
\hline
\end{tabular}

X-ray diffraction analysis is shown in table1.3. The types of minerals are simple; the chalcopyrite is the available metal mineral. The main non-metallic minerals are quartz, kaolin and ankerite.

\section{Flotation Separations}

The circuit of flotation is shown in Fig 1.

Grinding fineness. Water glass as dispersant $400 \mathrm{~g} / \mathrm{t}$ and xanthate as collector $170 \mathrm{~g} / \mathrm{t}$, the circuit of flotation is shown in Fig 1, the grinding fineness was researched and the effect of grinding fineness is shown in table 2.1 .

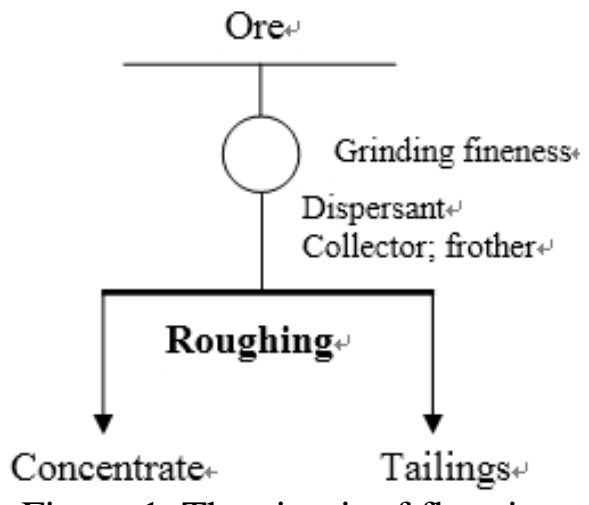

Figure 1. The circuit of flotation

Table 2.1 the effect of grinding fineness

\begin{tabular}{cccccc}
\hline \multirow{2}{*}{-200} & heading & $\begin{array}{c}\text { Weight } \\
\text { /g }\end{array}$ & Yield/\% & grade/\% & recovery/\% \\
\hline \multirow{2}{*}{$60 \%$} & concentrate & 38.1 & 7.65 & 8.82 & 83.72 \\
& tailings & 460.2 & 92.35 & 0.142 & 16.28 \\
\multirow{2}{*}{$80 \%$} & concentrate & 39.8 & 8.01 & 8.23 & 89.74 \\
& tailings & 456.8 & 91.99 & 0.082 & 10.26 \\
\multirow{2}{*}{$90 \%$} & concentrate & 31.7 & 6.31 & 10.64 & 90.86 \\
& tailings & 471 & 93.69 & 0.072 & 9.14 \\
\multirow{2}{*}{$95 \%$} & concentrate & 39.2 & 7.9 & 8.71 & 92.57 \\
& tailings & 456.8 & 92.1 & 0.06 & 7.47 \\
\hline
\end{tabular}

From table 2.1, the optimal grinding fineness is $90 \%$. 
The dosage of dispersant. The grinding fineness as $90 \%$, water glass as dispersant and xanthate as collector $170 \mathrm{~g} / \mathrm{t}$, the circuit of flotation is shown in Fig 1, the dosage of water glass was researched and the effect of the dosage of water glass is shown in table 2.2.

From the table 2.2, the optimal dosage of water glass is $400 \mathrm{~g} / \mathrm{t}$.

The dosage of collector. The grinding fineness as $90 \%$, water glass as dispersant $400 \mathrm{~g} / \mathrm{t}$ and xanthate as collector, the circuit of flotation is shown in Fig 1, the dosage of xanthate was researched and the effect of the dosage of xanthate is shown in table 2.3.

Table 2.2 the effect of the dosage of water glass

\begin{tabular}{cccccc}
\hline \multirow{2}{*}{ water glass g/t } & heading & $\begin{array}{c}\text { Weight } \\
/ \mathrm{g}\end{array}$ & $\begin{array}{c}\text { Yield } \\
/ \%\end{array}$ & Grade /\% & $\begin{array}{c}\text { Recovery } \\
/ \%\end{array}$ \\
\hline \multirow{2}{*}{0} & concentrate & 34 & 6.85 & 9.82 & 92.56 \\
& tailings & 462.5 & 93.15 & 0.058 & 7.44 \\
\multirow{2}{*}{400} & concentrate & 31 & 6.23 & 10.26 & 95.51 \\
& tailings & 466.9 & 93.77 & 0.032 & 4.49 \\
\multirow{2}{*}{700} & concentrate & 34 & 6.83 & 10.39 & 9.56 \\
& tailings & 464 & 93.17 & 0.035 & 90.44 \\
\multirow{2}{*}{1000} & concentrate & 32.6 & 6.56 & 10.34 & 9.49 \\
& tailings & 464.2 & 93.44 & 0.039 & 90.51 \\
\hline
\end{tabular}

Table 2.3 the effect of the dosage of xanthate

\begin{tabular}{cccccc}
\hline \multirow{2}{*}{ xanthate g/t } & heading & $\begin{array}{c}\text { Weight } \\
\text { /g }\end{array}$ & Yield /\% & Grade /\% & $\begin{array}{c}\text { Recovery } \\
/ \%\end{array}$ \\
\hline \multirow{2}{*}{100} & concentrate & 35 & 7.02 & 9.52 & 92.66 \\
& tailings & 463.3 & 92.98 & 0.057 & 7.34 \\
\multirow{2}{*}{135} & concentrate & 38.4 & 7.73 & 9.1 & 92.03 \\
& tailings & 458.4 & 92.27 & 0.066 & 7.97 \\
\multirow{2}{*}{170} & concentrate & 31 & 6.23 & 10.26 & 95.51 \\
& tailings & 466.9 & 93.77 & 0.032 & 4.49 \\
\multirow{2}{*}{205} & concentrate & 43.8 & 8.84 & 7.82 & 93.85 \\
& tailings & 451.7 & 91.16 & 0.0497 & 6.15 \\
\hline
\end{tabular}

From the table 2.3, the optimal dosage of xanthate is $170 \mathrm{~g} / \mathrm{t}$.

\section{Conclusion}

The grinding fineness as $90 \%$, water glass as dispersant $400 \mathrm{~g} / \mathrm{t}$ and xanthate as collector $170 \mathrm{~g} / \mathrm{t}$, two-stage scavenging and three-stage cleaning, at this conditions, 22.65\% copper was obtained with a recovery of $89.85 \%$.

\section{References}

1. D. Xixiang, in: Crushing and grinding (Metallurgical Industry Press, Beijing 2006).

2. D. Xixiang: The Study of Ball Size in ore fine grinding process. Yunnan Metallurgy, Vol. (5) 1986, p.12 17.

3. Z. Chunshui: Discuss the Effect of the Grinding Concentration on the Grinding. China Tungsten Industry, Vol. (2)1998, P. 25 27.

4. Z. Chunshui: The Effect of the Concentration on the Grinding. Metallic Ore Dressing Abroad, Vol. 6 1998, p. 13 15. 